\title{
Radiofrequency Ablation vs. Cryoablation for Localized Hepatocellular Carcinoma: A Propensity-matched Population Study
}

\author{
JIMMY XU, CHRISTOPHER NODA, ABIGAIL ERICKSON, MAHATI MOKKARALA, \\ RESMI CHARALEL, RAJA RAMASWAMY, YU TAO and OLAGUOKE AKINWANDE \\ Department of Radiology, Mallinckrodt Institute of Radiology, \\ Washington University in St Louis School of Medicine, St. Louis, MO, U.S.A.
}

\begin{abstract}
Background/Aim: To compare overall survival (OS) and liver cancer-specific survival (LCSS) of Surveillance, Epidemiology and End Results (SEER) hepatocellular carcinoma (HCC) database patients treated with cryoablation (cryo) or radiofrequency ablation (RFA). Materials and Methods: This was a retrospective review of Stage I or II HCC patients from the SEER database treated with cryo and RFA from 2004-2013. Kaplan-Meier and Cox regressions were performed on pooled and propensity-matched cohort. Results. Out of 3,239 patients, RFA showed a significant survival advantage over cryo in liver cancer specific survival (LCSS) $(H R=1.634 p=0.0004)$. A total of 91 propensity-matched pairs had similar OS (HR=1.006 $p=0.9768)$, but no difference in LCSS was observed between the groups [HR=1.412 (95\%CI=0.933-2.137) $p=0.1023]$. Survival Cox models did not reveal treatment type as an independent prognostic factor. Conclusion: Propensity-matched cohort showed no significant difference in terms of OS and LCSS was found for patients treated with either cryo or RFA for localized HCC.
\end{abstract}

Hepatocellular carcinoma (HCC) is the fifth most common cause of cancer-related death in the United States with a mortality second only to lung cancer worldwide (1). The standard of care for surgical candidates includes surgical resection and/or liver transplantation for early stage HCC. Only a small minority of patients are candidates for surgical treatment with curative intent (2). Thermal ablation (TA) has been

Correspondence to: Olaguoke Akinwande, MD, Assistant Professor, Department of Radiology, Washington University in St Louis School of Medicine, Mallinckrodt Institute of Radiology, $216 \mathrm{~S}$ King's highway Blvd, St Louis, MO 63110, U.S.A. Tel: +1 314 7477222, e-mail: oakinwa@wustl.edu

Key Words: Hepatocellular carcinoma, radiofrequency ablation, cryoablation, surveillance epide-miology and end results database, propensity matching, liver cancer specific survival. established as an alternative to surgical resection for certain patient populations who are poor surgical candidates or refusing surgery $(3,4)$. TA treatments offer a potential survival benefit for early-stage HCC patient populations, with this benefit approaching that of surgical resection in certain populations (5).

Heat-based TA modalities include radiofrequency and microwave ablation whereas cryoablation relies on freezing the tissue of interest (6). Of the heat-based modalities, radiofrequency ablation (RFA), which is the one best evaluated in the literature, uses conductive heat transfer from an alternating current to achieve an ablation zone via coagulative necrosis (6). RFA technical limitations include impedance from charred tissue and relative tissue susceptibility to heat sink effects. Conversely, cryoablation (cryo) causes cell damage by cooling the tissue to -20 to $-35^{\circ} \mathrm{C}$ forming intracellular and extracellular ice formation that can lead to extracellular osmolarity shifts and subsequent cell death (7). Cryoablation technical limitations include requiring longer freezing times as well as multiple cryoprobes in order to maintain cooling efficiency (8-10).

While there is a larger body of literature evaluating RFA because of its earlier development (11) (Table I), cryoablation literature continues to expand specifically in regard to its role in liver tumor management (Table I). Historically, RFA has been implemented in cirrhotic patients because heat-based methods have relatively lower bleeding complication rates $(12,13)$. However, cryoablation technology has evolved to include thinner probes and using helium-argon instead of liquid nitrogen as a cryogen (14). Cryoablation is often the modality of choice when precision is needed for lesions near vulnerable structures since the ablation zone can be monitored real time on intraprocedural CT. This element as well, as cryoablation having a smaller overall ablation zone has led many physicians to expand its use in HCC (15). At the time of this publication, however, there has been a limited number of studies comparing outcomes including overall survival (OS) and liver cancer-specific survival (LCSS) in patients treated with cryoablation or RFA. 
Table I. Literature review of RFA and cryoablation for HCC.

\begin{tabular}{|c|c|c|c|c|}
\hline Study, year & $\begin{array}{l}\text { No. of } \\
\text { pts }\end{array}$ & $\begin{array}{l}\text { Study } \\
\text { details }\end{array}$ & $\begin{array}{c}\text { Median recurrence free } \\
\text { survival (mos) }\end{array}$ & $\begin{array}{c}\text { Median overall } \\
\text { survival (mos) }\end{array}$ \\
\hline Chen et al., 2006 (21) & 180 & Prospective RCT (vs. Surgical Resection) & $>60$ & $>60$ \\
\hline Huang et al., 2010 (3) & 230 & Prospective RCT (vs. Surgical Resection) & 36 & $>60$ \\
\hline Lencioni et al., 2005 (22) & 206 & Prospective (single arm) & 36 & 49 \\
\hline N'Kontchou et al., 2009 (23) & 235 & Prospective (single arm) & 19.7 & 48 \\
\hline Choi et al., 2007 (24) & 570 & Prospective (single arm) & $>60$ & $>60$ \\
\hline Tateishi et al., 2005 (25) & $319^{*}$ & Prospective (single arm) & N/A & $>60$ \\
\hline Adam et al., 2002 (26) & 33 & Retrospective & 11 & 18 \\
\hline Chen et al., 2011 (27) & $40^{*}$ & Retrospective & $\sim 24$ & $>36$ \\
\hline Shimizu et al., 2009 (28) & 15 & Prospective (single arm) & N/A & $>36$ \\
\hline Adams et al., 2002 (26) & 31 & Retrospective (cryoablation) & 10 & 21 \\
\hline Zhou et al., 2009 (29) & 124 & Prospective & N/A & $* 31.25,17.41,6.82$ \\
\hline Xu et al., 2009 (8) & 130 & Prospective & N/A & 33.6 \\
\hline Yang et al., 2012 (30) & 300 & Retrospective & $7.1 * *$ & 22 \\
\hline Zhou et al., 1998 (31) & 235 & Prospective & N/A & $>36$ \\
\hline
\end{tabular}

*Treatment-naïve patients. Authors also reported survival rates for 345 patients with tumor recurrence who subsequently received radiofrequency ablation. Bold corresponds to cryoablation literature review for HCC patients.

A recent systematic review attempted to address this gap by analyzing 7 geographically diverse prospective studies ( 3 from Europe, 3 from United States, and 1 from China). The authors found that there was no significant difference in OS between RFA and cryoablation (16). One drawback of the above study was that the percentage of patients with a recorded survival was only $12 \%$ of the population for cryoablation and $16 \%$ of the population for the RFA cohort. In addition, the three studies in American populations were not created with complete demographic balancing between treatment groups, which raises concerns about the influence of confounding variables in their analysis.

To address some of the shortcomings in the literature, we used the National Cancer Institute Surveillance, Epidemiology, and End Results (SEER) database to compare OS and LCSS in patients with localized HCC (AJCC stage I and II) treated with RFA and cryoablation between 2004-2013. This large dataset will average patient factors and institutional treatment variations in a "real world" patient population to elucidate differences between the two treatment modalities.

\section{Materials and Methods}

This study was exempt from institutional review board approval and was completed in accordance with the National Cancer Institute SEER user agreement. The SEER database collects cancer statistics pooled from 18 registries, covering approximately $28 \%$ of the American population, from diverse geographic locations throughout the country. Collected data includes patient demographics, primary tumor site, tumor morphology, stage at diagnosis, first course of treatment, and survival. Data collection was standardized to ensure that individual state registry data is acceptable for subsequent data pooling (1).
Patient population. A total of 3,239 patients diagnosed with AJCC HCC Stage I or II (tumor grade $\leq 2$, node involvement grade $=0$, metastasis grade $=0$ ) treated with either RFA or cryo from 2004-2013 were identified using the SEER database. TA techniques included both percutaneous and surgical approaches (laparoscopic and open) because the database did not distinguish between the two techniques. Patients with primary tumors other than HCC were excluded from this study.

Demographic and clinical data. Demographic and clinical data included sex, age, race, cancer stage, tumor grade, tumor size, American Joint Committee on Cancer (AJCC) cancer stage, alphafetoprotein (AFP), and liver fibrosis score.

Outcomes. OS was the primary outcome and LCSS was the secondary outcome. LCSS refers to patients who died from causes other than their primary cancer burden. Overall survival in the SEER database was stratified by either primary death by cancer, secondary death by cancer, or secondary death by another cause. The latter two cohorts were excluded from the LCSS group. Outcomes were calculated using total months survived, which was included in the database. Overall survival, refers to patients who were alive at the end of the study.

Statistical analysis. Baseline demographics and clinical characteristics were compared with the Chi-Squared test for categorical variables and non-parametric Wilcoxon sum rank test for continuous variables. Kaplan-Meier survival curve was performed for OS and LCSS in patients with HCC who underwent either cryoablation or RFA as a first-line ablation treatment modality. The log-rank test was used to examine the statistical significance of the differences observed between the groups. A Cox proportional hazards model was also applied to compute hazard ratios (HR) and 95\% confidence intervals (95\% CI). A competing risk analysis was applied to LCSS to estimate the cumulative incidence of LCSS, where death of other causes was defined as a competing risk event to the main events. A 2-tailed $p$ - 
Table II. Baseline demographic and clinical patient characteristics, unmatched groups.

\begin{tabular}{|c|c|c|c|c|}
\hline Characteristic & $\begin{array}{l}\text { Overall } \\
\% \text { (no.) }\end{array}$ & $\begin{array}{c}\text { Cryoablation } \\
\% \text { (no.) }\end{array}$ & $\begin{array}{l}\text { RFA } \\
\% \text { (no.) }\end{array}$ & $p$-Value \\
\hline Gender & & & & 0.5311 \\
\hline Female & $25.1(813)$ & $22.3(21)$ & $25.2(792)$ & \\
\hline Male & $74.9(2426)$ & 77.7. (73) & $74.8(2353)$ & \\
\hline Race & & & & 0.006 \\
\hline AI & $1.6(51)$ & 0 & $1.6(51)$ & \\
\hline API & $20.9(677)$ & $8.5(8)$ & $21.3(669)$ & \\
\hline Black & $11.5(372)$ & $8.5(8)$ & $11.6(364)$ & \\
\hline Unknown & $0.4(13)$ & 0 & $0.4(13)$ & \\
\hline White & $65.6(2126)$ & $83(78)$ & $65.1(2048)$ & \\
\hline Cancer stage & & & & 0.7228 \\
\hline Stage I & $71.8(2325)$ & $73.4(69)$ & $71.7(2256)$ & \\
\hline Stage II & $28.2(914)$ & $26.6 .(25)$ & $28.3(889)$ & \\
\hline Tumor grade & & & & 0.2408 \\
\hline I (well) & $43(529)$ & $43.7(21)$ & $42.9(508)$ & \\
\hline II (moderately) & $45.9(565)$ & $39.6(19)$ & $46.2(546)$ & \\
\hline III (poorly) & $10.6(130)$ & $14.6(7)$ & $10.4(123)$ & \\
\hline IV (Undifferentiated) & $0.6(7)$ & $2.1(1)$ & $0.5(6)$ & \\
\hline AFP & & & & 0.9839 \\
\hline Fibrosis Score & & & & 0.0319 \\
\hline 0 & $5.4(176)$ & $5.3(5)$ & $5.4(171)$ & \\
\hline 1 & $31(1003)$ & 19.2. (18) & $31.3(985)$ & \\
\hline Unknown & $63.6(2060)$ & $75.5(71)$ & $63.2(1989)$ & \\
\hline Age mean (std) & $62.6(9.7)$ & $65.9(10.1)$ & $62.5(9.7)$ & 0.0008 \\
\hline $\begin{array}{l}\text { Tumor size median } \\
\text { (q1-q3) mm }\end{array}$ & $30.2(20-36)$ & $28(21-38)$ & $27(20-36)$ & 0.4595 \\
\hline
\end{tabular}

AI: American Indian; API: Asian Pacific Islander; AFP: alpha-fetoprotein.

value $<0.05$ was considered statistically significant. All analyses were performed within SAS (version 9.4; SAS, Cary, NC, USA).

Propensity matching. Propensity score matching was also applied to account for confounding demographic variables in this study population. This technique has been shown to resemble randomized controlled trials when applied to observational studies (17-19). Age, gender, race, cancer stage, tumor grade, tumor size, cancer stage and liver fibrosis score were included in the propensity matching model. Patients were matched in a 1:1 ratio using the caliper method (caliper $=0.25$ standard deviation. Matched pairs Cox regression models were used to estimate differences in overall survival between the treatment groups, with treatment as the dependent variable and background demographic and clinical factors as independent variables.

\section{Results}

Pooled cohort. A total of 3,239 patients ( $n=94$ cryo, $n=3145$ RFA) were included in the study. Before matching, the treatment groups were similar demographically with the exception of age, race and liver fibrosis score (Table II). The cryo group was significantly older (65.9 years \pm 10.1 vs. 62.5 years \pm 9.7 ). There were also racial differences, with a
Table III. Multivariate Cox Regression analysis results overall survival and liver cancer-specific survival (LCSS) for cryoablation and RFA: Backward select method was used.

\begin{tabular}{|c|c|c|c|c|}
\hline \multirow{2}{*}{$\begin{array}{l}\text { Parameter } \\
\text { Stage }\end{array}$} & \multirow[t]{2}{*}{$\operatorname{Pr}$} & \multirow[t]{2}{*}{$\begin{array}{c}\text { Hazard } \\
\text { Ratio }\end{array}$} & \multicolumn{2}{|c|}{$\begin{array}{l}\text { 95\% Confidence } \\
\text { Interval }\end{array}$} \\
\hline & & & & \\
\hline I & Refer & - & & \\
\hline II & 0.0017 & 1.77 & 1.24 & 2.52 \\
\hline \multicolumn{5}{|l|}{ Age } \\
\hline $\mathrm{U}=10$ & 0.0515 & 1.22 & 1.00 & 1.49 \\
\hline \multicolumn{5}{|l|}{ AFP } \\
\hline Normal & Refer & - & & \\
\hline Elevated & 0.0375 & 1.53 & 1.025 & 2.29 \\
\hline \multicolumn{5}{|l|}{ Tumor size } \\
\hline $\mathrm{U}=10$ & 0.0008 & 1.21 & 1.08 & 1.35 \\
\hline Race (LCSS) & 0.0034 & & & \\
\hline White & Refer- & & & \\
\hline AI & 0.2010 & 0.56 & 0.23 & 1.36 \\
\hline API & 0.0006 & 0.66 & 0.52 & 0.84 \\
\hline Black & 0.8799 & 1.02 & 0.77 & 1.35 \\
\hline Stage (LCSS) & 0.013 & & & \\
\hline I & Refer- & & & \\
\hline II & 0.0130 & 1.28 & 1.05 & 1.55 \\
\hline \multicolumn{5}{|l|}{ Age (LCSS) } \\
\hline $\mathrm{U}=10$ & 0.0025 & 1.16 & 1.05 & 1.27 \\
\hline \multicolumn{5}{|l|}{ AFP (LCSS) } \\
\hline Normal & Refer- & & & \\
\hline Elevated & 0.0005 & 1.42 & 1.17 & 1.74 \\
\hline \multicolumn{5}{|l|}{ Tumor (LCSS) } \\
\hline $\mathrm{U}=10$ & 0.0009 & 1.09 & 1.03 & 1.14 \\
\hline
\end{tabular}

AI: American Indian; API: Asian Pacific Islander; AFP: alpha-fetoprotein; LCSS: liver cancer specific survival.

larger majority of cryo patients identified as white (cryo: 83\%, $\mathrm{n}=78$; RFA: $65.1 \%, \mathrm{n}=2048$ ). The liver fibrosis score was also significantly different between the groups (cryo: fibrosis present $19.2 \% \mathrm{n}=18$; RFA: fibrosis present $31.3 \%$ $\mathrm{n}=985 ; p=0.0319$ ), although a sizable proportion of patients in both groups did not have a documented fibrosis score in the database (cryo: unknown fibrosis $75.5 \% \mathrm{n}=71$; RFA: unknown fibrosis $63.2 \% \mathrm{n}=1989$ ). There was no significant difference in overall survival in the two unmatched treatment groups $[\mathrm{cryo}=29$ months $(95 \% \mathrm{CI}=21-40$ months $), \mathrm{RFA}=41$ months (95\%CI=39-43 months) $p=0.0657]$ (Figure 1); however, RFA showed a significant LCSS advantage over cryo $[\mathrm{HR}=1.634(95 \% \mathrm{CI}=1.24-2.15) p=0.0004]$ (Figure 1).

Multivariate cox regression model on OS and LCSS showed that treatment type was not an independent prognostic factor; however, Asian/Pacific Islanders [HR=0.66 $(95 \% \mathrm{CI}=0.52-0.84), p<0.001]$, AJCC cancer stage $[\mathrm{HR}=1.28$ $(95 \% \mathrm{CI}=1.05-1.55) p<0.05]$, age $[\mathrm{HR}=1.16(95 \% \mathrm{CI}=1.05-$ 1.27) $p<0.05]$, AFP level $[\mathrm{HR}=1.42(95 \% \mathrm{CI}=1.17-1.74)$ $p<0.001]$, and tumor size $[\mathrm{HR}=1.09(95 \% \mathrm{CI}=1.03-1.14)$ $p<0.001]$ were significant prognostic factors for OS (Table 



Figure 1. Pooled SEER cohort survival curves. Left: Kaplan-Meier curve for unmatched groups shows that there is no significant difference in OS for patients treated with cryoablation compared with RFA. Right: The cumulative incidence functions for unmatched groups shows that there is a significantly higher probability of liver cancer specific death in the cryoablation group compared to the RFA group.
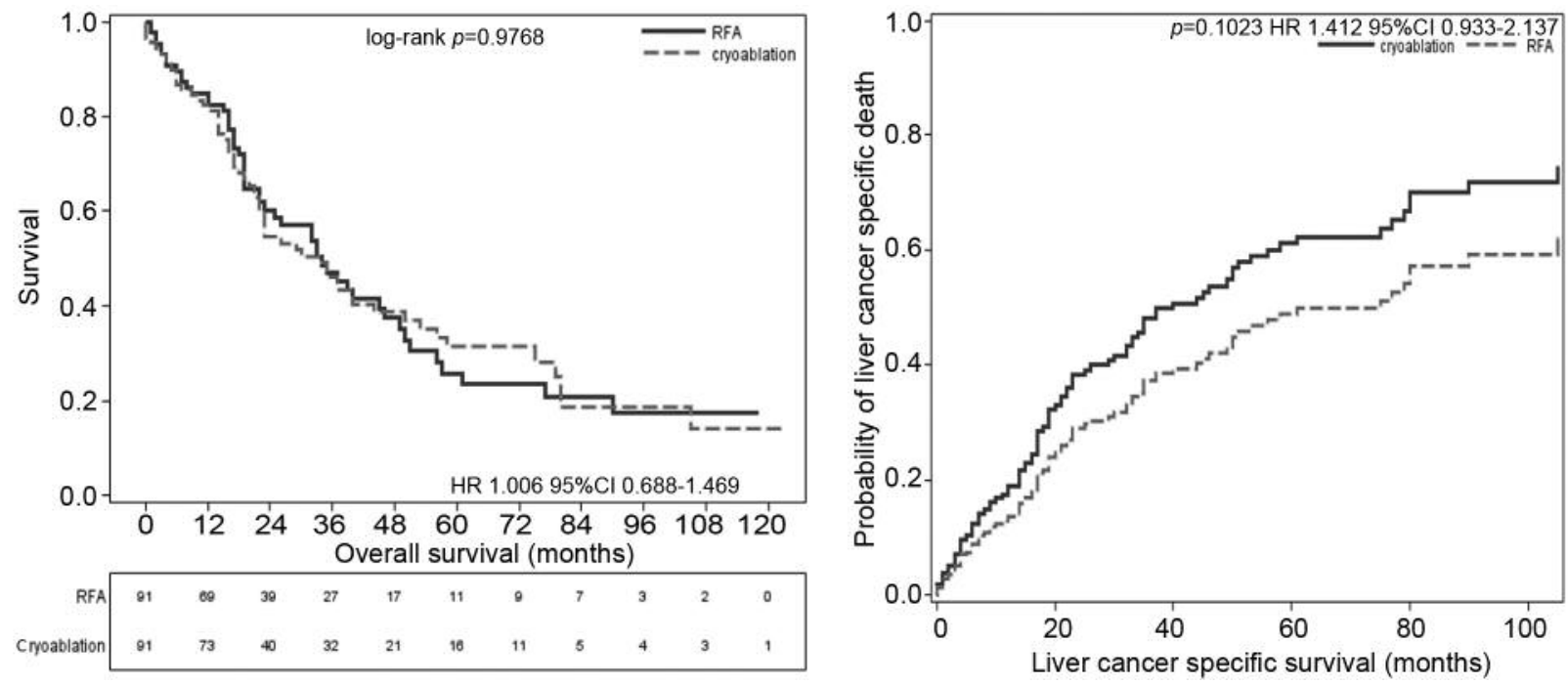

Figure 2. Matched SEER cohort survival curves. Left: Kaplan-Meier curve for propensity score-matched cohort shows that there is no significant difference in OS between the treatment groups. Right: The cumulative incidence functions for matched groups show that there is no significant difference in the probability of liver cancer specific death between the cryoablation and RFA treatment groups.

III). For LCSS, AJCC stage II [HR=1.77 (95\% CI=1.24-2.42) $p<0.01]$, AFP level [HR=1.53, $(95 \% \mathrm{CI}=1.025-2.29) p<0.05]$, and tumor size $[\mathrm{HR}=1.21(95 \% \mathrm{CI}=1.08-1.35) p<0.001]$ were independent prognosticators (Table III).

Propensity matched cohort. Propensity matching produced 91 pairs that had similar background variables (Table IV). In this population, there was similar OS between the treatment groups [HR=1.006 (95\% CI=0.688-1.469) $p=0.9768$ ] (Figure 2). However, in contrast to the pooled cohort, there was also no difference in LCSS between the groups $[\mathrm{HR}=1.412$ (95\% CI $=0.933-2.137) p=0.1023]$ (Figure 2). Of note, OS was 34 months $(95 \% \mathrm{CI}=22-46$ months) in the RFA group and 34 months (95\% CI=22-44 months) in the cryo group. 
Table IV. Demographic and clinical patient characteristics of propensity score matched group.

\begin{tabular}{|c|c|c|c|c|}
\hline Characteristic & $\begin{array}{l}\text { Overall \% C } \\
\text { (no.) }\end{array}$ & $\begin{array}{c}\text { Cryoablation } \% \\
\text { (no.) }\end{array}$ & $\begin{array}{c}\text { \% RFA \% } \\
\text { (no.) }\end{array}$ & $p$-Value \\
\hline Gender & & & & 0.7203 \\
\hline Female & $22(41)$ & $23.1(21)$ & $20.9(20)$ & \\
\hline Male & $78(142)$ & $76.9(70)$ & $79.1(72)$ & \\
\hline Race & & & & 0.5059 \\
\hline API & $11.5(21)$ & $8.8(8)$ & $14.3(13)$ & \\
\hline Black & $8.8(16)$ & $8.8(8)$ & $8.8(8)$ & \\
\hline White & $79.7(145)$ & $82.4(75)$ & $76.9(70)$ & \\
\hline Cancer stage & & & & 0.6243 \\
\hline Stage I & $70.9(129)$ & $72.5(66)$ & $69.2(63)$ & \\
\hline Stage II & $29.1(53)$ & $27.5(25)$ & $30.8(28)$ & \\
\hline Tumor grade & & & & 0.6491 \\
\hline I (well) & $50(46)$ & $46.7(21)$ & $53.2(25)$ & \\
\hline II (moderately) & $32.6(30)$ & $37.8(17)$ & 27.7 (13) & \\
\hline III (poorly) & $16.3(15)$ & $15.5(7)$ & $17(8)$ & \\
\hline IV (Undifferentiated) & $1.1(1)$ & 0 & $2.1(1)$ & \\
\hline AFP & & & & 0.9031 \\
\hline Fibrosis Score & & & & 0.5019 \\
\hline 0 & $26.1(12)$ & $21.7(5)$ & $30.4(7)$ & \\
\hline 1 & $73.9(34)$ & $78.3(18)$ & $69.6(16)$ & \\
\hline Age mean(std) & $64.9(10.8)$ & $65.6(9.6)$ & $64.2(11.9)$ & 0.3665 \\
\hline $\begin{array}{l}\text { Tumor size median } \\
\text { (q1-q3) mm }\end{array}$ & $28.5(21-38)$ & $28(21-38)$ & $29(20-39)$ & 0.9125 \\
\hline
\end{tabular}

API: Asian Pacific Islander; AFP: alpha-feto protein; LCSS: liver cancer specific survival.

\section{Discussion}

The current literature has not come to a consensus regarding the comparative efficacy of cryoablation versus RFA in the early stage HCC patient population. A recent study by Wang et al. enrolled 360 patients with Child-Pugh class A or B cirrhosis and non-metastatic primary HCC with one or two lesions $\leq 4 \mathrm{~cm}$ in a multicenter randomized controlled trial (20). The patients were split equally into cryo $(n=180)$ and RFA ( $n=180)$ arms and the primary endpoint was local tumor progression. They found that there was a significant difference in local tumor progression at 1,2 , and 3 years follow up $(3 \%, 7 \%$, and $7 \%$ for cryo and $9 \%, 11 \%$, and $11 \%$ for RFA, $p=0.041)$. In another study, where local tumor control was the primary endpoint, 119 consecutive patients

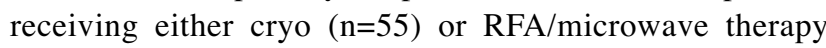
$(n=64)$ were prospectively reviewed. The authors reported improved local tumor control with the cryo group compared to the RFA/microwave therapy group (10). Although these studies were important additions to the general literature, they did not help to establish the relative performance of each device as it relates to survival.

A study by Wu et al., comparing the survival benefit of cryoablation versus RFA did not find a statistically significant difference between the two treatments (16). Our study supports their conclusion, but includes a more diverse American population, using pooled data collected during 2004-2013. In our propensity matched study, there was no statistically significant difference in OS or LCSS between early stage HCC patients treated with either RFA or cryoablation. Given that the groups were evenly matched across multiple background variables, we reason that this study provides a firm observation that there is no survival difference between the two modalities.

This study has limitations that are the direct result of using data compiled from the SEER database. First, there are a variety of diagnostic factors that are not recorded in the database including performance status, number of tumor(s), tumor location, medical comorbidities, Childs-Pugh-Turcotte score, etiology of chronic liver disease, presence/severity of portal hypertension, differentiating intraoperative versus percutaneous approach, post-treatment toxicity, and administration of systemic therapy. Because these factors are known predictors of survival following TA, this analysis is unable to account for the effect these factors could have on patient outcomes. Nevertheless, we suspect that these data points are likely to be randomly distributed in the SEER database and their influence on the data would, thus, be minimal. Further prospective studies that could address the limitations of the SEER database, including randomized controlled trials, are needed to better delineate the survival benefits of these two ablation modalities. Other trials are investigating the role of cryoablation in biliary tract carcinomas or in combination with other transarterial therapies.

Our SEER database retrospective analysis ultimately found no significant difference in terms of OS and LCSS for patients treated with first-line cryoablation or RFA.We anticipate a blending of both ablation and embolization procedures in the future in order to provide further local HCC tumor control beyond what just ablation can provide. Together ablation and embolization therapies could improve outcomes over just one treatment modality in itself.

\section{Conflicts of Interest}

No conflicts of interest exist regarding this study.

\section{References}

1 Overview of the SEER Program. In: National Cancer Institute, 2017.

2 Saraswat VA, Pandy G and Shetty S: Treatment algorithms for managing hepatocellular carcinoma. J Clin Exp Hepatol 4: S8089, 2014.

3 Huang J, Yan L, Cheng Z, Wu H, Du L, Wang J, Xu Y and Zeng $\mathrm{Y}$ : A randomized trial comparing radiofrequency ablation and surgical resection for HCC conforming to the Milan criteria. Ann Surg 252: 903-912, 2010. 
4 Lee DH, Lee JM, Lee JY, Kim SH, Yoon JH, Kim YJ, Han KJ and Choi BI: Radiofrequency ablation of hepatocellular carcinoma as first-line treatment: long-term results and prognostic factors in 162 patients with cirrhosis. Radiology 270: 900-909, 2014.

5 Cucchetti A, Piscaglia F, Cescon M, Ercolani G and Pinna AD: Systematic review of surgical resection vs radiofrequency ablation for hepatocellular carcinoma. World J Gastroenterol 2013: 4106-4118, 2013.

6 Hinshaw JL, Lubner MG, Ziemlewicz TJ, Lee FT and Brace CL: Percutaneous tumor ablation tools: microwave, radiofrequency, or cryoablation - what should you use and why? Radiographics 34: 1344-1362, 2014.

7 Gervais DA and Arellano RS: Percutaneous tumor ablation for hepatocellular carcinoma. AJR Am J Roentgenol 197: 789-794, 2011.

8 Xu KC, Niu LZ, Zhou Q, Hu YZ, Guo DH, Liu ZP, Lan B, Mu F, Li YF and Zuo JS: Sequential use of transarterial chemoembolization and percutaneous cryosurgery for hepatocellular carcinoma. World J Gastroenterol 15: 3664-3669, 2009.

9 Niu LZ, Li JL and Xu KC: Percutaneous Cryoablation for Liver Cancer. J Clin Transl Hepatol 2: 182-188, 2014.

10 Ei S, Hibi T, Tanabe M, Itano O, Shinoda , Kitago M, Abe Y, Yagi H, Okabayashi K, Sugiyma D, Wakabayashi $G$ and Kitagawa Y: Cryoablation provides superior local control of primary hepatocellular carcinomas of $>2 \mathrm{~cm}$ compared with radiofrequency ablation and microwave coagulation therapy: an underestimated tool in the toolbox. Ann Surg Oncol 22: 12941300, 2015.

11 Livraghi T, Goldberg SN, Lazzaroni S, Meloni F, Solbiati L and Gazelle GS: Small hepatocellular carcinoma: treatment with radio-frequency ablation versus ethanol injection. Radiology 210: 655-661, 1999.

12 Lencioni RA, Allgaier HP, Cioni D, Olschewski M, Deibert P, Crocetti L, Frings H, Laubenberger J, Zuber I, Blum HE and Bartolozzi C: Small hepatocellular carcinoma in cirrhosis: randomized comparison of radiofrequency thermal ablation versus percutaneous ethanol injection. Radiology 228: 235-240, 2003.

13 Bilchik AJ, Wood TF, Allegra D, Tsioulias GJ, Chung M, Rose DM, Ramming KP and Morton DL: Cryosurgical ablation and radiofrequency ablation for unresectable hepatic malignant neoplasms: a proposed algorithm. Arch Surg 135: 657-662, 2000.

14 Soong KD: Percutaneous cryoablation for hepatocellular carcinoma. Clin Mol Hepatol 22: 509-515, 2016.

15 McWilliams JP, Yamamoto S, Raman SS, Loh CT, Lee EW, Liu DM and Kee ST: Percutaneous ablation of hepatocellular carcinoma: current status. J Vasc Interv Radiol 21: S204-213, 2010.

16 Wu S, Hou J, Ding Y, Wu F. Hu Y, Jiang Q, Mao P and Yang Y: cryoablation versus radiofrequency ablation for hepatic malignancies: a systematic review and literature-based analysis. Medicine (Baltimore) 94: e2252, 2015.

17 Austin PC: An introduction to propensity score methods for reducing the effects of confounding in observational studies. Multivariate Behav Res 46: 399-424, 2011.

18 Coca-Perraillon M: Local and global optimal propensity score matching. In: SAS Global Forum, 2007.

19 Rosenbaum PR: The central role of the propensity score in observational studies for causal effects. Biometrika 70: 41-55, 1983.
20 Wang C, Wang H, Yang W, Hu K, Xie H, Hu KQ, Bai W, Dong Z, Lu Y, Zeng Z, Lou M, Wang H, Gao X, Chang X, An L, Qu $\mathrm{J}$, Li J and Yang Y: Multicenter randomized controlled trial of percutaneous cryoablation versus radiofrequency ablation in hepatocellular carcinoma. Hepatology 61: 1579-1590, 2015.

21 Chen MS, Li JQ, Zheng Y, Guo RP, Liang HH, Zhang YQ, Lin $\mathrm{XJ}$ and Lau WY: A prospective randomized trial comparing percutaneous local ablative therapy and partial hepatectomy for small hepatocellular carcinoma. Ann Surg 243: 321-328, 2006.

22 Lencioni R, Cioni D, Crocetti L, Franchini C, Pina CD, Lera J and Bartolozzi C: Early-stage hepatocellular carcinoma in patients with cirrhosis: long-term results of percutaneous imageguided radiofrequency ablation. Radiology 234: 961-967, 2005.

23 N'Kontchou G, Mahmoudi A, Aout M, Ganne-Carrie N, Grando V, Coderc E, Vicaut E, Trinchet JC, Sellier N, Beaugrand M and Seror O: Radiofrequency ablation of hepatocellular carcinoma: long-term results and prognostic factors in 235 Western patients with cirrhosis. Hepatology 50: 1475-1483, 2009.

24 Choi D Lim HK, Rhim H, Kim YS, Lee WJ, Paik SW, Koh KC, Lee JH, Choi MS and Yoo BC: Percutaneous radiofrequency ablation for early-stage hepatocellular carcinoma as a first-line treatment: long-term results and prognostic factors in a large single-institution series. Eur Radiol 17: 684-692, 2007.

25 Tateishi R, Shiina S, Teratani T, Obi S, Sato S, Koike Y, Fujishima T, Yoshida H, Kawabe T and Omata M: Percutaneous radiofrequency ablation for hepatocellular carcinoma. An analysis of 1000 cases. Cancer 103: 1201-1209, 2005

26 Adam R, Hagopian EJ, Linhares M, Krissat J, Savier E, Azoulay D, Kunstlinger F, Castaing D and Bismuth H: A comparison of percutaneous cryosurgery and percutaneous radiofrequency for unresectable hepatic malignancies. Arch Surg 137: 1332-1339; discussion 1340, 2002.

27 Chen HW, Lai EC, Zhen ZJ, Cui WZ, Liao S and Lau WY: Ultrasound-guided percutaneous cryotherapy of hepatocellular carcinoma. Int J Surg 9: 188-191, 2011.

28 Shimizu T, Sakuhara Y, Abo D, Hasegawa Y, Kodama Y, Endo $\mathrm{H}$, Shirato $\mathrm{H}$ and Miyasaka K: Outcome of MR-guided percutaneous cryoablation for hepatocellular carcinoma. J Hepatobiliary Pancreat Surg 16: 816-823, 2009.

29 Zhou L, Yang YP, Feng YY, Lu YY, Wang CP, Wang XZ, An LJ, Zhang $X$ and Wang FS: Efficacy of argon-helium cryosurgical ablation on primary hepatocellular carcinoma: a pilot clinical study. Ai Zheng 28: 45-48, 2009.

30 Yang Y, Wang C, Lu Y, Bai W, An L, Qu J, Gao X, Chen Y, Zhou L, Wu Y, Feng Y, Zhang M, Chang X and Lv J: Outcomes of ultrasound-guided percutaneous argon-helium cryoablation of hepatocellular carcinoma. J Hepatobiliary Pancreat Sci 19: 674684, 2012.

31 Zhou XD and Tang ZY: Cryotherapy for primary liver cancer. Semin Surg Oncol 14: 171-174, 1998 